\title{
Two for one: A self-management plan coupled with a prescription sheet for children with asthma
}

\author{
Francine M Ducharme MD MSc ${ }^{1,2}$, Francisco Noya $\mathrm{MD}^{3}$, David McGillivray MD ${ }^{4}$, Sandy Resendes $\mathrm{MSc}^{5}$, \\ Stéphanie Ducharme-Bénard ${ }^{5}$, Roger Zemek MD ${ }^{6}$, Sanjit Kaur Bhogal MSc ${ }^{5}$, Rachel Rouleau BPh MSc ${ }^{7}$
}

FM Ducharme, F Noya, D McGillivray, et al. Two for one: A self-management plan coupled with a prescription sheet for children with asthma. Can Respir J 2008;15(7):347-354.

BACKGROUND: Despite strong recommendations in the asthma guidelines, the use of written self-management plans remains low among asthmatic patients.

OBJECTIVES: To develop a written self-management plan, based on scientific evidence and expert opinions, in a format intended to facilitate its dispensing by health care professionals, and to test the perception of its relevance and clarity by asthmatic children, adolescents and adults.

METHODS: Inspired by previously tested self-management plans, surveys of asthma educators, expert opinions and the 2004 Canadian Asthma Guidelines, the authors simultaneously developed French and English versions of a written self-management plan that coupled with a prescription. The self-management plan was tested in parents and their asthmatic children (aged one to 17 years), and it was revised until $85 \%$ clarity and perceived relevance was achieved.

RESULTS: Ninety-seven children and their parents were interviewed. Twenty per cent had a self-management plan. On the final revision, nearly all items were clear and perceived relevant by $85 \%$ or more of the interviewees. Two self-management plans were designed for clinics and acute care settings, respectively. The plans are divided into three control zones identified by symptoms with optional peak flow values and symbolized by traffic light colours. They are designed in triplicate format with a prescription slip, a medical chart copy and a patient copy.

CONCLUSION: The written self-management plans, based on available scientific evidence and expert opinions, are clear and perceived to be relevant by children, adolescents and their parents. By incorporating the prescription and chart copies, they were designed to facilitate dispensing by physicians in both clinics and acute care settings.

Key Words: Adolescents; Adults; Asthma; Children; Clarity; Instrument; Prescription; Self-management; Survey; Written action plan

Tational and international guidelines (1-3) recommend 1 the use of a written self-management plan for all patients with asthma. In the context of a comprehensive asthma education and medical follow-up program, action plans clearly improve asthma morbidity (4-6). Yet, the ownership of a selfmanagement plan by Canadian patients remains disappointingly low, ranging from $8 \%$ to $11 \%$ in children and adults with

\section{Deux pour un : Plan d'auto-prise en charge allié à un feuillet d'ordonnance pour les enfants asthmatiques}

HISTORIQUE : Malgré les recommandations catégoriques formulées dans les directives sur l'asthme, l'emploi de plans écrits d'auto-prise en charge reste peu répandu chez les patients asthmatiques.

OBJECTIFS : Développer un plan écrit d'auto-prise en charge fondé sur des preuves scientifiques et l'opinion d'experts susceptible d'être davantage utilisé par les professionnels de la santé et vérifier la perception de sa pertinence et sa clarté auprès des enfants, des adolescents et des adultes asthmatiques.

MÉTHODES : Inspirés par des plans d'auto-prise en charge ayant déjà été testés, par des sondages réalisés auprès d'éducateurs dans le domaine de l'asthme, par l'opinion des experts et par les directives canadiennes de 2004 sur l'asthme, les auteurs ont développé simultanément un plan écrit d'auto-prise en charge en français et en anglais, allié à un feuillet d'ordonnance. Le plan d'auto-prise en charge a été mis à l'essai auprès de parents et de leurs enfants asthmatiques (âgés d'un à 17 ans) et il a été graduellement amélioré jusqu'à l'obtention d'un résultat de $85 \%$ aux chapitres de la clarté et de la pertinence perçue.

RÉSULTATS : Les auteurs ont interrogé 97 enfants et parents. Vingt pour cent avaient en main un plan d'auto-prise en charge. Lors de la révision finale du document, presque tous les éléments étaient clairs et considérés pertinents par $85 \%$ ou plus des personnes interrogées. Deux plans d'auto-prise en charge ont été conçus pour les cliniques et le contexte des soins aigus, respectivement. Les plans se subdivisent en trois zones de contrôle établies en fonction des symptômes et des valeurs de débit de pointe optionnelles et symbolisées par les différentes couleurs d'un feu de circulation. Ils sont conçus en triple copie et joints à un feuillet d'ordonnance, comprenant une copie pour le dossier médical et une copie pour le patient.

CONCLUSION : Les plans écrits d'auto-prise en charge qui se fondent sur les preuves scientifiques existantes et sur l'opinion des experts sont clairs et considérés pertinents par les enfants, les adolescents et leurs parents. Incorporant un feuillet d'ordonnance et une copie pour les dossiers médicaux, ils sont conçus pour être faciles distribuer par les médecins, tant dans les cliniques que le contexte des soins aigus.

asthma $(7,8)$. Clearly, the delivery of written self-management plans requires additional time and effort on the part of physicians, particularly when the instructions are hand-written on a blank piece of paper (9).

Although most health professionals recognize the advantages of self-management plans, they have limited knowledge of what to include in the plan to optimize care and communication with

${ }^{1}$ Clinical Research on Childhood Asthma; ${ }^{2}$ Department of Pediatrics, University of Montreal; ${ }^{3}$ Division of Allergy and Clinical Immunology;

${ }^{4}$ Division of Pediatric Emergency Medicine, Department of Pediatrics, Montreal Children's Hospital, McGill University Health Centre;

${ }^{5}$ Division of Pediatrics, Research Centre, CHU Sainte-Justine, Montreal, Quebec; ${ }^{6}$ Division of Pediatric Emergency Medicine, Department of

Pediatrics, Children's Hospital for Eastern Ontario, Ottawa, Ontario; ${ }^{7}$ Quebec Network for Asthma and COPD Education, Department of

Pharmacy, Centre de Santé et de Services Sociaux de la Vieille Capitale, Quebec City, Quebec

Correspondence: Dr Francine M Ducharme, Department of Pediatrics, CHU Sainte-Justine, Room 7939, 3175 Cote Sainte-Catherine, Montreal,

Quebec H3T 1C5. Telephone 514-345-4931 ext 4398, fax 514-345-4822, e-mail francine.m.ducharme@umontreal.ca 
patients (10). According to the standard definition (2), a written self-management plan should focus on the management of exacerbations. Yet, daily anti-inflammatory therapy is the most effective strategy to prevent exacerbations (11). Contrary to common practice, there is little evidence that step-up therapy with inhaled corticosteroids reduces the severity of exacerbations compared with maintaining a stable dose (12-14). The evidence suggests that maintenance therapy should constitute the cornerstone of a self-management plan for most children and adults. While the amount of information provided in the plan is positively related to its perceived relevance by patients (15), few studies have focused on identifying key elements of an effective self-management plan (16).

The objectives of the present study were to develop a unique written self-management plan for children, adolescents and adults based on scientific evidence and expert opinion, to test the self-management plan for clarity and perceived relevance in children and their parents, and to create a suitable design that facilitates its adoption by health care professionals.

\section{METHODS}

\section{Item generation}

To identify key elements to include in the self-management plan, the Cochrane Airways Group Clinical Trials Register was searched for review articles and randomized controlled trials testing asthma self-management plans in children, published until March 2006. Adult and pediatric self-management plans were solicited from published randomized controlled trials whenever available, from educators of the 90 Quebec asthma education centres of the Quebec Network of Asthma and COPD (Réseau québécois de l'asthme et de la MPOC), and from our international consultant committee. These consultants represented different health care professionals (physicians, pharmacists, nurse educators), specialties (pediatrics, adult and pediatric respiratory medicine, emergency medicine, nursing), practice settings (community and academic), and various geographic regions in Quebec and outside Canada (United Kingdom, France and Australia); they provided extensive feedback on the first prototype and the final version of the selfmanagement plan.

\section{Item reduction}

To identify key elements to include in, and trivial or confusing elements to remove from, the self-management plan, a questionnaire was mailed to 129 educators at the 90 asthma education centres across Quebec; there was no repeat mailing for nonresponders. The questionnaire solicited feedback on the following aspects of an ideal action plan: overall format, general messages and language, self-assessment, recommendations and asthma control zones. The educators rated the importance of each item on a Likert scale of 1 (not important) to 5 (very important). Item scores that averaged 4 or more were considered to be important and selected for inclusion; items that averaged 3.5 or more were considered to be desirable, and included whenever possible.

\section{Item presentation and scaling}

The layout and presentation were inspired from adult and pediatric self-management plans, review articles and recommendations from the international consultants. The design was guided by the specific intention of coupling the self-management plan with a prescription.

\section{Testing for clarity}

Design: Between May and August 2005, a survey of a convenience sample of children and their parents, who were approached in the emergency department, asthma and respiratory clinics, and hospital wards of the Montreal Children's Hospital (Montreal, Quebec), was conducted. The study was approved by the Scientific and Institutional Review Boards of the Montreal Children's Hospital. Informed consent was obtained from parents and children seven years of age or older.

Study participants: Participants included children aged one to 17 years (and their parents) who presented with asthma (or suspected asthma, which was supported by current ownership of asthma medication) and with adequate French or English language skills. Children were excluded if they had a chronic pulmonary disease (ie, bronchopulmonary dysplasia or cystic fibrosis) or were too sick to complete the interview.

Procedure: Clarity and perceived relevance were tested with cognitive interviews in children aged seven to 17 years and their parents, as well as in parents of children aged one to six years. Specifically, participants were instructed to read aloud the selfmanagement plan so that words or elements that were problematic could be identified. Because of the time constraints of the recruitment setting, feedback on the clarity and relevance of the overall format (layout and graphics) was prioritized. Depending on the allotted time, feedback on one or more of the following sections was requested: general messages and language, self-assessment of asthma control, asthma control zones and nonpharmacological recommendations. Finally, the selfmanagement plan was completed with fictitious instructions, and interviewees were probed with scenarios and questions to ensure understanding. Aiming for a grade 2 elementary reading level (seven years of age), the self-management plan was tested in school-aged children and adolescents, and parents were specifically asked about the suitability of the self-management plan for themselves as potential patients. Several iterative versions were developed until clarity and perceived relevance was achieved in $85 \%$ of participants. Using the back-translation technique, the French and English versions were simultaneously designed.

\section{Statistics}

Based on the elaboration of previous instruments (each in French and English) (17), it was estimated that the feedback from 30 to 50 children and 50 to 75 parents on iterative versions would be required to achieve $85 \%$ clarity and perceived relevance on the final version. Clarity and perceived relevance were reported as proportions. Medians were reported with interquartile range (25th to 75 th percentile).

\section{Instrument development}

\section{RESULTS}

Five sources of information guided the development of the initial version of the self-management plan. First, three Cochrane reviews of randomized controlled trials examining the efficacy of self-management plans were identified $(16,18,19)$; two reviews $(16,19)$ specifically identified key characteristics associated with an effective plan. The superiority of symptombased over peak flow-based action plans (19) led to the primary use of symptoms to describe the three control zones (16) in our action plan, with optional peak flow values. Second, a survey of nurses involved in childhood asthma care in the 
TABLE 1

Rating of items for inclusion in the self-management plan based on a survey of Quebec asthma educators

\begin{tabular}{|c|c|c|c|}
\hline Item & Important $(\geq 4)$ & Desirable (3.5-3.9) & Not important $(<3.5)$ \\
\hline \multirow[t]{6}{*}{ Overall format } & Use of traffic light colours & Linked to a calendar of symptoms & Orientation from top to bottom \\
\hline & Pamphlet format & Coupled with a prescription sheet & One-page format \\
\hline & Carton/thick paper & Referring to inhaler by commercial & \\
\hline & Graphics specific to child versus adult & names and colour & \\
\hline & & Contract wording (using "I") & \\
\hline & & Copy for patient medical file & \\
\hline \multirow{11}{*}{$\begin{array}{l}\text { General messages } \\
\text { and languages }\end{array}$} & Possibility of living a normal life & Recognition of asthma as a chronic disease & \\
\hline & Environmental control & Recognition of compliance as a challenge & \\
\hline & Nonpharmacological measures & & \\
\hline & Regular medical follow-up & & \\
\hline & Asthma education & & \\
\hline & Adherence & & \\
\hline & Importance of self-management & & \\
\hline & Criteria for asthma control & & \\
\hline & Inhalation technique & & \\
\hline & Treatment of comorbidities & & \\
\hline & Avoidance of smoking & & \\
\hline \multirow[t]{4}{*}{ Asthma control zones } & $\begin{array}{l}\text { Emphasis on: urgent visit if loss of } \\
\text { control; preventive management; and }\end{array}$ & Treatment of rhinitis or allergic conjunctivitis & $\begin{array}{l}\text { Recommendations for nasal hygiene } \\
\text { during colds }\end{array}$ \\
\hline & asthma control criteria & & Emphasis on treatment of flare-ups \\
\hline & Instruction on beta ${ }_{2}$-agonist use & & \\
\hline & Characteristics of medications & & \\
\hline \multirow[t]{6}{*}{ Space for } & Additional criteria & Environmental recommendations & Follow-up appointment date \\
\hline & Instructions to step-up therapy & Phone contact of educator & Phone contact of physician \\
\hline & Other recommendations & RQAM Web site & Phone contact of pharmacist \\
\hline & Recommendation for exposure to & & Emergency phone contact \\
\hline & asthma triggers & & Phone contact of clinic or hospital \\
\hline & & & Treatment of comorbidities \\
\hline
\end{tabular}

Endorsed items were rated for their importance on a Likert scale of 1 (not important) to 5 (very important): items rated 4 or more were considered important for inclusion in the self-management plan; those that averaged 3.5 to 3.9 were considered desirable and were included whenever possible; while items rated lower than 3.5 were considered not important. RQAM Réseau québécois de l'asthme et de la MPOC (Quebec Network of Asthma and COPD)

United Kingdom identified characteristics of asthma action plans that promoted self-management in school-aged children, which inspired our first prototype (20). Third, with a response rate of $42 \%$, the survey of the Quebec asthma educators allowed us to prioritize the items perceived to be most important (Table 1). Fourth, the layout, presentation and description of the asthma control zones were inspired by a collection of action plans tested in trials or used in Quebec or abroad, and were revised with the feedback of the international consultant committee. Finally, the self-management plan was conceived in a way that applied to children, adolescents and adults; could be printed in triplicate, combining a prescription, a medical chart copy and the take-home action plan to facilitate its dispensing by physicians; and could be used in both clinics and acute care settings. The first prototype to be tested met almost all recommendations.

\section{Testing for clarity}

Of the 122 children approached, 112 were eligible. With a participation rate of $87 \%, 97$ children and parents were interviewed on one or more of the five sections (Figure 1); 38 patients tested the French model, and 59 patients tested the English model. The characteristics of the patients are depicted in Table 2. The median age of the children was nine years, with four completed years of school. One-third of mothers and fathers had a high school education or less. Only 25\% of the children had previously seen or had a self-management plan, with less than $3 \%$ currently using one. Most parents (86\%) perceived their child's asthma as being well controlled, a perception shared by $56 \%$ of children old enough to answer. However, $50 \%$ of children presented at least two criteria indicative of poor asthma control.

Comments and suggestions were elicited from participants for three iterative versions before the final version. Table 3 illustrates the clarity and perceived relevance of the third version, as well as the overall score with all versions combined. An overwhelming proportion of subjects endorsed the concepts of traffic light colours, achievable asthma control, ability to lead a healthy and active life, and the five nonpharmaceutical recommendations. The concept of asthma chronicity was reworded without the word 'chronic', because two-thirds of children did not understand the word. Finally, 30\% of participants remained confused with the terms 'holding chamber' and/or 'spacer', preferring the use of the commercial names, which could not be avoided; space constraints impeded the substitution of these terms with a picture. 


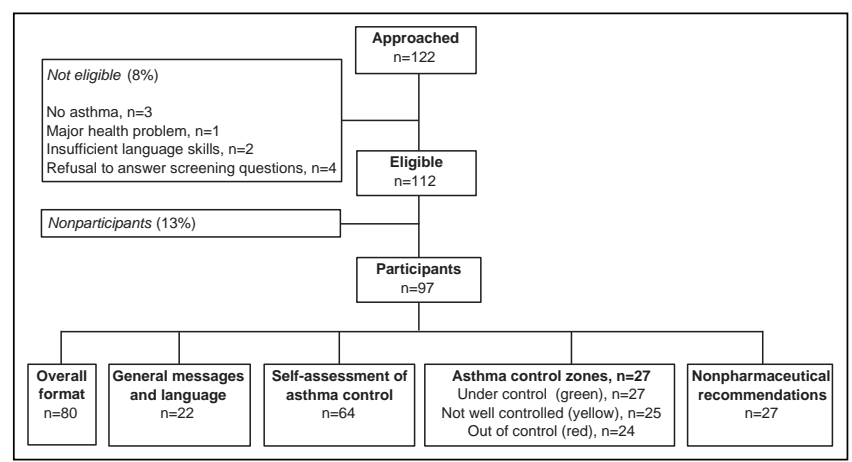

Figure 1) The selection of participants

With regard to self-assessment of asthma control, the use of a modified version of the validated Asthma Quiz for Kidz (17) was endorsed by the majority of participants (Figure 2). The title, the description and the instructions of each control zone were overwhelmingly clear (Table 3 ). The proportion of patients who rated as important the opportunity to record their personal symptoms, decreased from $88 \%$ (version 1) to $14 \%$ (version 3); this space was thus removed. Of interest, $78 \%$ of patients expressed a wish for a matching calendar to record symptoms and medications.

With regard to the potential need for distinct self-management plans for children, adolescents and adults, 97\% of the 80 parents and the 22 asthmatic adolescents surveyed endorsed the action plan for their personal use, and specifically its language, layout and criteria for asthma control. With $15 \%$ of parents requesting fewer graphics, the final version retained only smiley faces and traffic light colours to serve as a unique selfmanagement plan for all age groups.

Although the initial intention was to develop a unique selfmanagement plan for use in both clinics and acute care settings, most participants were confused by the unfilled sections (ie, unfilled red section for clinic patients; unfilled green and yellow sections for those treated in the acute care setting). Because physicians also shared this confusion, two self-management plans, one for each setting, were created and harmonized with each other. The self-management plan used in clinics focuses on the maintenance of asthma control (green zone) and the appropriate measures to take in case of deterioration (yellow zone) (Figure 2). The plan conceived for the acute care setting focuses on the treatment following an unscheduled medical consultation for acute asthma. Both are available in English and French versions.

The concept of coupling the self-management plan with a prescription was endorsed by l'Ordre des pharmaciens $d u$ Québec, because the plan adhered to prescription guidelines by providing space for the date, physician's name, signature and license number, as well as a copy of the plan for the medical chart. It is available as a triplicate document; the prescription is the first copy, a replica of the self-management plan for the medical chart is the second copy, and the self-management plan for the patient is the third copy.

More than $88 \%$ of the participants perceived the final version of the self-management plan as relevant, with no difference across age groups (one to six years, seven to 12 years, 13 to 17 years). This final version achieved more than $85 \%$ clarity and perceived relevance for almost all of its components, with the few exceptions mentioned above. With minor modifications, the final version was approved for use in children and
TABLE 2

Characteristics of participants

\begin{tabular}{|c|c|c|}
\hline Characteristic & $\begin{array}{l}\text { French } \\
(n=38)\end{array}$ & $\begin{array}{c}\text { English } \\
(n=59)\end{array}$ \\
\hline Male subjects, \% & 50 & 53 \\
\hline Age, years, median (interquartile range) & $9.5(3-12)$ & $9(6-12.5)$ \\
\hline \multicolumn{3}{|l|}{ Race, $\%$} \\
\hline Caucasian & 79 & 72 \\
\hline Black & 3 & 9 \\
\hline Asian & 5 & 9 \\
\hline Multiracial and others & 13 & 10 \\
\hline \multicolumn{3}{|l|}{ Education } \\
\hline $\begin{array}{l}\text { Child - number of years of schooling from } \\
\text { grade 1, median (interquartile range) }\end{array}$ & $4(3-5)$ & $4(2-6)$ \\
\hline \multicolumn{3}{|l|}{ Mother, \% } \\
\hline Elementary & 5 & 10 \\
\hline High school & 24 & 21 \\
\hline College, trade school or other & 39 & 37 \\
\hline University (or other) & 32 & 32 \\
\hline \multicolumn{3}{|l|}{ Previous experience with a written action plan, $\%$} \\
\hline Ever seen or ever had one & 26 & 24 \\
\hline Current ownership & 16 & 5 \\
\hline Current use & 0 & 5 \\
\hline \multicolumn{3}{|l|}{ Self-described asthma symptomatology, \% } \\
\hline Infrequent flare-ups & 74 & 70 \\
\hline Frequent flare-ups & 21 & 12 \\
\hline Persistent symptoms & 5 & 18 \\
\hline \multicolumn{3}{|c|}{ Asthma control in past year, median (interquartile range) } \\
\hline Number of emergency department visits & $1(0.5-3)$ & $0(0-1)$ \\
\hline Days of school absences & $0(0-4)$ & $1(0-2.5)$ \\
\hline Asthma Quiz for Kidz* (17) & $1.5(0-3)$ & $2(0-2)$ \\
\hline Maintenance medication, \% & 45 & 24 \\
\hline \multicolumn{3}{|l|}{ Home management of flare-ups, $\%$} \\
\hline None & 3 & 7 \\
\hline Short-acting beta ${ }_{2}$-agonists & 18 & 22 \\
\hline $\begin{array}{l}\text { Inhaled glucocorticoids (same dose as } \\
\text { maintenance) }\end{array}$ & 37 & 17 \\
\hline Increased dose of inhaled glucocorticoids & 39 & 54 \\
\hline Oral steroids & 3 & 0 \\
\hline
\end{tabular}

*This validated six-item questionnaire reports the number of indicators of poor asthma control, namely day and night symptoms, rescue beta ${ }_{2}$-agonist use, exercise limitation in the preceding seven days, as well as absenteeism and exacerbation in the preceding month

adults by the Conseil du Médicament under the recommendation of the experts from its advisory groups and by international consultants; it was endorsed by the Quebec Network of Asthma and COPD (Réseau québécois de l'asthme et de la MPOC), and various provincial stakeholders.

\section{DISCUSSION}

In an iterative process, we developed and tested two written asthma self-management plans for use in clinics and acute care settings, respectively. We used the back-translation technique to develop the French and English versions simultaneously. The control zones were defined by symptoms identified through a literature review and confirmed by patient interviews. The self-management plans were based on a prototype elaborated from surveys of asthma educators from the United 
TABLE 3

Clarity and perceived relevance of items in the self-management plan

\begin{tabular}{|c|c|c|c|c|}
\hline & \multicolumn{2}{|c|}{ Clarity* } & \multicolumn{2}{|c|}{ Importance $^{\dagger}$} \\
\hline & Third version & All versions & Third version & All versions \\
\hline General format & $(n=26)$ & $(n=80)$ & $(n=26)$ & $(n=80)$ \\
\hline Reference to inhaler by commercial names & - & - & 92 & 93 \\
\hline Wording as a contract using "I" & - & - & 92 & 93 \\
\hline Overall action plan & - & - & 89 & 83 \\
\hline Intent of the written action plan & 89 & 90 & 89 & 96 \\
\hline Message of a healthy and active lifestyle & 100 & 96 & 100 & 96 \\
\hline Asthma control achievable & 89 & 86 & - & - \\
\hline Asthma portrayed as a chronic disease & 67 & 55 & 78 & 73 \\
\hline Self-assessment of asthma control & $(n=19)$ & $(n=64)$ & $(n=19)$ & $(n=64)$ \\
\hline Avoidance of smoking & 92 & 93 & 92 & 96 \\
\hline Regular medical follow-up & 85 & 78 & 85 & 85 \\
\hline Asthma education & 85 & 89 & 85 & 82 \\
\hline Personal objectives & 92 & 89 & 85 & 82 \\
\hline “Asthma under control” zone (green) & $(n=12)$ & $(n=27)$ & $(n=12)$ & $(n=27)$ \\
\hline Title & 92 & 70 & - & - \\
\hline Description of well-controlled asthma & 92 & 93 & 100 & 100 \\
\hline Instruction to take daily medication & 100 & 93 & - & - \\
\hline "Asthma not well controlled" zone (yellow) & $(n=6)$ & $(n=25)$ & $(n=6)$ & $(n=25)$ \\
\hline Title & 83 & 92 & - & - \\
\hline Instruction on acute management ${ }^{\ddagger}$ & 86 & 83 & 100 & 96 \\
\hline
\end{tabular}

*Values are presented as per cent of patients who answered yes; ${ }^{\dagger}$ Values are presented as per cent of patients who answered important or somewhat important; fFor acute care version only

Kingdom and Quebec. The versions were revised until 85\% clarity and perceived relevance were obtained. After feedback and revision, the final version was approved by the Direction scientifique du suivi et de l'usage optimal of the Conseil $d u$ Médicament and its committees, our international consultant committee and expert groups. These self-management plans transcend the traditional concept of former self-management plans by putting emphasis on preventive management; facilitating self-assessment by linking the asthma quiz and control zones; including a prescription and a medical chart copy; applying to children, adolescents and, most likely, adults; being available in French and English; and conveying the five basic concepts of the Canadian Asthma Consensus, namely, control of the environment, adherence to treatment, self-assessment and self-management, regular medical follow-up and asthma education.

The plan promotes the self-assessment of asthma control using symptoms and self-management (using three colour zones), two concepts overwhelmingly endorsed by patients. These decisions are supported by methodologically strong Cochrane reviews. Indeed, a pediatric review stressed the greater effectiveness of symptom-based over peak flow-based action plans for reducing emergency department visits (19). Gibson and Powell (16) associated the use of four or less action points to lower asthma morbidity in adults. The proposed action plan calls for regular self-assessment using a modified version of the validated Asthma Quiz for Kidz (17). The modified Asthma Quiz shares many similarities with a validated adult questionnaire that used the same five criteria and cut-off value of one, as an indicator of poor control (21). The yellow zone description, linked but not limited to the Asthma Quiz, serves to identify an acute loss of control, thus allowing rapid therapeutic adjustment. These criteria are in tune with most published and unpublished written self-management plans (16,22-24). They were approved by expert groups and endorsed by an overwhelming majority of participants who interestingly, 
A

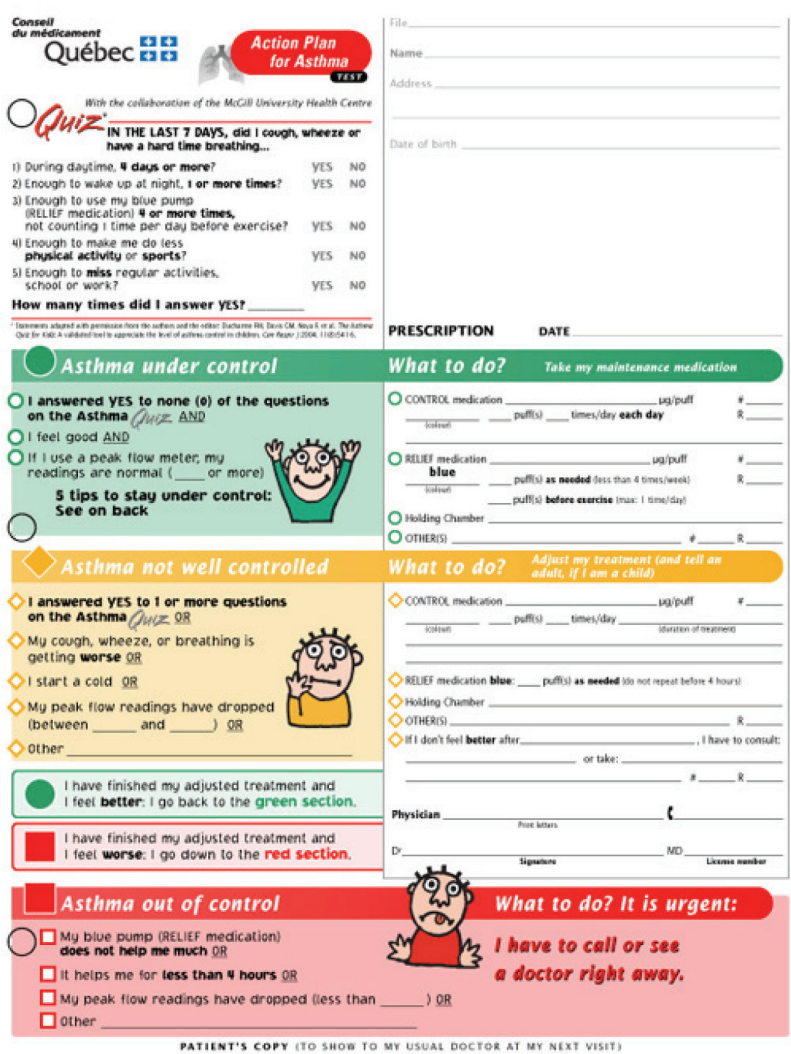

\section{B}

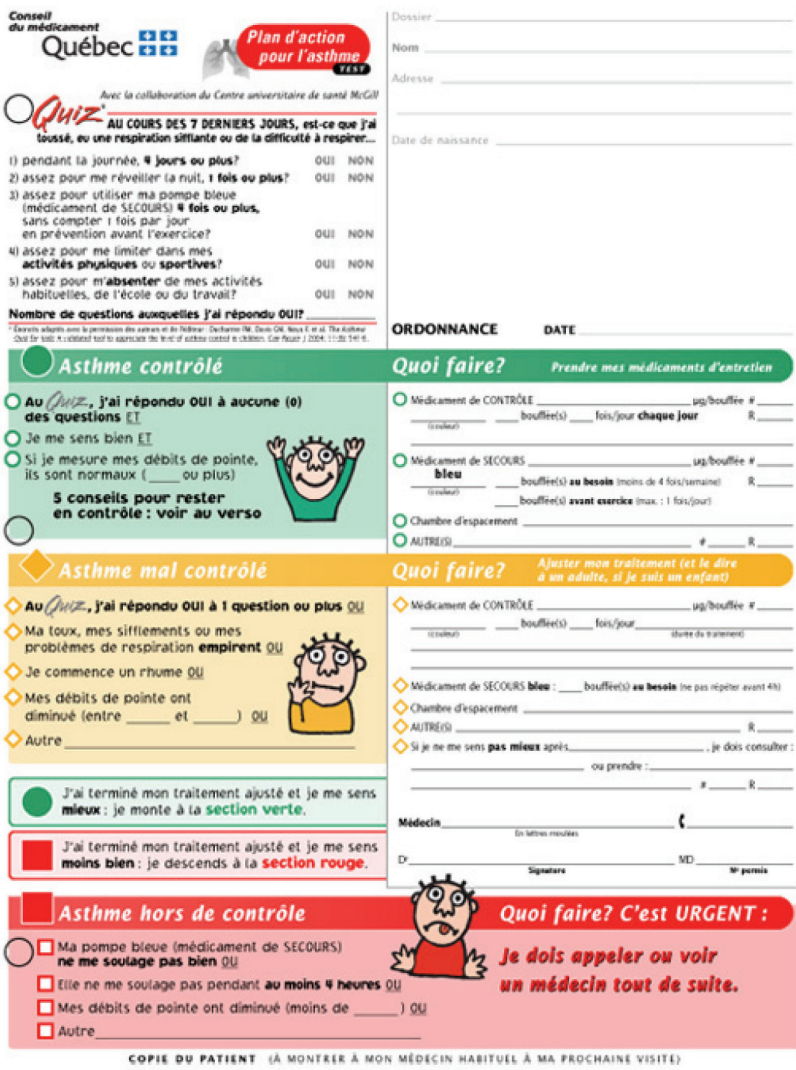

\section{Q10 Action Plan for Asthma cisst}

Everyone with asthma
CAN LEAD AN ACTNE LIFE!

Asthma is a cilisease that affects my lungs (bronchi) EvERy DAY, even between asthma attacks.

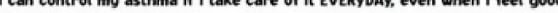
My Action plan will help me : - Keep my asthma under control everyday.

5 TIPS TO STAY UNDER CONTROL D Avoia what triggers my asthma.

- I must avoid smoking or being in a house or a car where someone smokes.

-1 agree to:

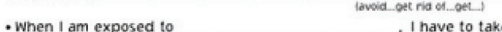

- If I get a cold, I will use my Action Plan, blow my nose and clean it with saline water

2 Take my maintenance medication (green section). times a day. if needed.

- I review the way I use my pumps (innalers) with my pharmacist or my asthma ecoucotor.

- Corrections:

- My tricks to remember to take my medication are:

3 Retake the Asthma Ouvz regularly.

4 see my doctor regularly.

- My doctor

will review with me my Action Plan in:

5 Get some netp.

- Health professionals are there to help me use my Action Plan:

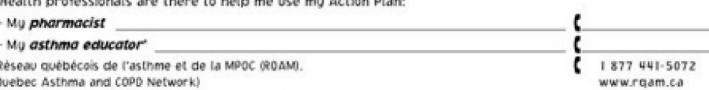

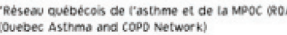

MY PERSONAL OBJECTIVES

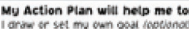

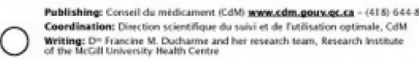

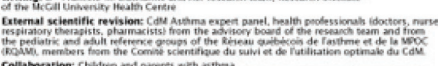

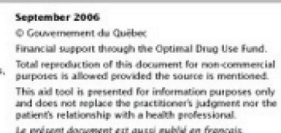

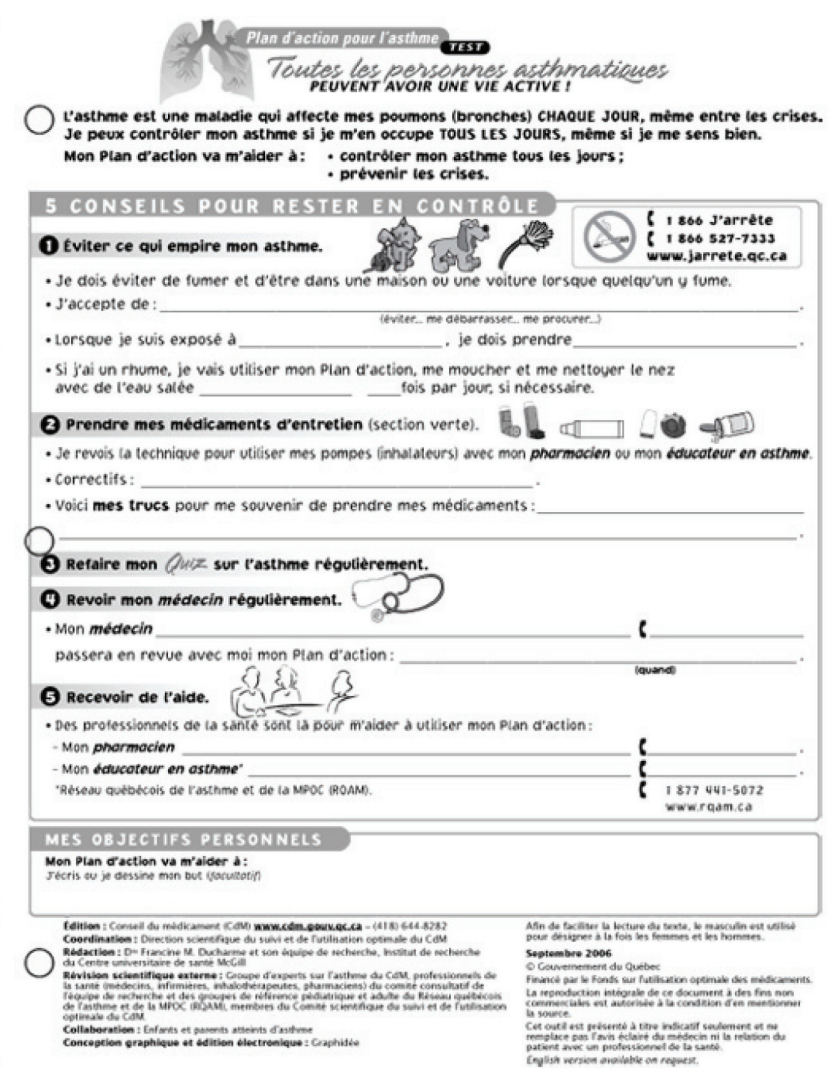

Figure 2) English (A) and French (B) versions of the self-management plan for clinics. The left panel represents the recto (the pharmacy copy), and is reproduced in triplicate format with the second copy for the medical chart and the third copy for the patient. The right panel represents the verso of the written action plan, and comprises general messages about asthma, the purpose of the action plan and the five steps to maintain asthma control. The self-management plan for the acute care setting will be available on request 
declined the option of adding other symptoms. These plans were also developed to facilitate self-management in children, adolescents and adults through a second-grade language level that is clear but not infantile, attractive graphics and format, clear links between self-assessment and self-management instructions, simple fill-in-the-blank recommendations for medications, and the five steps to maintain asthma control described on the verso of the action plan.

To our knowledge, this is the first published written action plan for use at discharge following an acute care visit. In this busy setting, where physicians (25) and patients (26) tend to adhere poorly to standard discharge recommendations, our intent was to clearly identify the acute care visit as a treatment failure, reverse the perception of asthma as an episodic condition (27), and create an opportunity to initiate adequate longterm asthma management.

Three features were intended to facilitate the dispensing of the self-management plan by physicians and asthma educators, namely, the use of the fill-in-the-blank method to reduce the amount of writing, the design as an educational tool, and the coupling of the self-management plan with a prescription. Whether use of these specific self-management plans will improve the quality of physicians' recommendation for, and patients' compliance with, maintenance therapy, asthma education and medical follow-up, beyond that observed with existing plans, remains to be tested.

We recognize the following limitations of the present study. Space constraints have compelled us to remove some items, such as instructions on how to use the inhaler device and a description of the role of each medication; experience will allow us to validate or invalidate these removals. Although 80 parents were specifically asked to give their perspective as potential users of the plan, we have not tested the plan in a large number of asthmatic adults. Self-management plans may need to be revised over time, because knowledge progresses in the recognition and treatment of loss of asthma control. A matching calendar of symptoms has been solicited by most participants as a means to facilitate the use of the action plan.

The generalizability of the present study results merits careful consideration. Although conducted in a pediatric university hospital, the participants appeared to be comparable with several population-based surveys in Canada in terms of the disconnection between actual and perceived asthma control, underuse of daily preventive medication and low ownership of action plans $(8,28)$. Finally, the self-management plan has yet to be tested for its effectiveness in promoting self-management and self-assessment in clinics and acute care settings in various populations, including adults.

The proposed self-management plans are based on probing data, as well as recommendations from local and international physicians, nurses and educators. They were revised with patients in an iterative way until more than $85 \%$ clarity and perceived relevance was obtained. These plans are offered as tools to facilitate self-assessment, self-management and communication between patients and health care professionals (physicians, pharmacists, asthma educators) (29).

ACKNOWLEDGEMENTS: The authors are indebted to the many children and their parents who participated enthusiastically in this project, providing precious feedback and suggestions to shape the asthma self-management plan. The authors also thank Francine Lacoste and her team for the rapid and outstanding translation services. They gratefully acknowledge the members of the international consultant committee, namely, those from Australia (Mark Lee and Bruce Whitehead), from Lyon, France (Dominique Blouin), from Canada (Denis Bérubé, Patrick Daigneault, Mario-Eddy Dumas, Héléne Leblond, Catherine Lemière, Alain Moreau, and Sandra Woods) and from the United Kingdom (Peter Callary and Linda Milnes). The authors are indebted to the staff members of the Conseil du Médicament (Diane Blais, Francine Currodeau and Danielle Doyon), the members of Le Comité scientifique du suivi et de l'usage optimal du Conseil du Médicament (Johanne Blais, Régis Blais, Danielle Doyon, Céline Dupont, Claudine Laurier, Diane Lamarre, Maurice Saint-Laurent and Jeannine Tellier-Cormier), the members of the Committee of Asthma Experts of the Conseil $d u$ Médicament (Denis Bérubé, Johanne Blais, Jacques Bouchard, Louis-Philippe Boulet, André Cartier, Pierre Ernst, Pierre Gaudreault, Martine Grondin, Manon Labrecque, Catherine Lemière, Claudine Laurier and Rachel Rouleau) and the members of the Quebec Network of Asthma and COPD (Réseau québécois de l'asthme et de la MPOC) including Patricia Coté, who reviewed, commented and endorsed the final version. The authors sincerely thank Jonathan Morin, Sabrina Drudi and Jennifer Frei who participated in patient recruitment, iterative revisions of the action plan and data entry, and Janine Dumont who assisted in the manuscript preparation.

FUNDING: This work was supported by a research contract from the Fonds de Partenariat sur l'usage optimal of the Conseil du Médicament, Ministry of Health and Social Services, Québec. It was presented at the Society for Pediatric Research in San Francisco, California, in May 2006 and at the European Respiratory Society Meeting in Munich, Germany, in September 2006.

\section{REFERENCES}

1. National Asthma Education and Prevention Program. Expert Panel Report: Guidelines for the Diagnosis and Management of Asthma Update on Selected Topics 2002 (EPR - Update 2002). Bethesda: National Heart, Lung, and Blood Institute, 2002.

2. Global Initiative for Asthma. Global strategy for asthma management and prevention, 2006. <www ginasthma org> (Version current at September 15, 2008).

3. Lemiere C, Bai T, Baltzan M, et al; on behalf of the Canadian Asthma Consensus Group of the Canadian Thoracic Society. Adult Asthma Consensus Guidelines Update 2003. Can Respir J 2004;11(Suppl A):9A-18A.

4. Gibson PG, Coughlan J, Wilson AJ, et al. Self-management education and regular practitioner review for adults with asthma. Cochrane Database Syst Rev 2000:CD001117.

5. Guevara JP, Wolf FM, Grum CM, Clark NM. Effects of educational interventions for self management of asthma in children and

adolescents: Systematic review and meta-analysis. BM 2003;326:1308-9

6. Agrawal SK, Singh M, Mathew JL, Malhi P. Efficacy of an individualized written home-management plan in the control of moderate persistent asthma: A randomized, controlled trial. Acta Paediatr 2005;94:1742-6.

7. The National Asthma Control Task Force. The Prevention and Management of Asthma in Canada: A major Challenge Now and in the Future. $<$ http://www.phac-aspc.gc.ca/publicat/pmapca00/index.html> (Version current at September 15, 2008).

8. Fitzgerald JM, Boulet LP, McIvor RA, Zimmerman S, Chapman KR. Asthma control in Canada remains suboptimal: The Reality of Asthma Control (TRAC) study. Can Respir J 2006;13:253-9.

9. Sheares BJ, Du Y, Vazquez TL, Mellins RB, Evans D. Use of written treatment plans for asthma by specialist physicians. Pediatr Pulm 2007; 42:348-56. 
10. Moffat M, Cleland J, van der MT, Price D. Poor communication may impair optimal asthma care: a qualitative study. Family Practice 2007;24:65-70.

11. Pauwels RA, Pedersen S, Busse WW, et al. Early intervention with budesonide in mild persistent asthma: A randomised, double-blind trial. Lancet 2003;361:1071-6.

12. Reddel HK, Barnes DJ, Exacerbation AP. Pharmacological strategies for self-management of asthma exacerbations. Eur Respir J 2006;28:182-99.

13. Fitzgerald JM, Becker A, Sears MR, et al. Doubling the dose of budesonide versus maintenance treatment in asthma exacerbations. Thorax 2004;59:550-6.

14. Fitzgerald JM, Boulet LP, Follows RM. The concept trial: A 1-year, multicenter, randomized, double-blind, double-dummy comparison of a stable dosing regimen of salmeterol/fluticasone propionate with an adjustable maintenace dosing regimen of formoterol/budesonide in adults with persistent asthma. Clin Ther 2005;27:393-406.

15. Beauchesne MF, Levert V, El Tawil M, Labrecque M, Blais L. Action plans in asthma. Can Respir J 2006;13:306-10.

16. Gibson PG, Powell H. Written action plans for asthma: An evidence-based review of the key components. Thorax 2004;59:94-9

17. Ducharme FM, Davis GM, Noya F, Rich H, Ernst P. The Asthma Quiz for Kidz: A validated tool to appreciate the level of asthma control in children. Can Respir J 2004;11:541-6.

18. Toelle BG, Ram FS. Written individualised management plans for asthma in children and adults. Cochrane Database Syst Rev 2002:CD002171.

19. Bhogal S, Zemek R, Ducharme FM. Written action plans for asthma in children. Cochrane Database Syst Rev 2006:CD005306.
20. Milnes LJ, Callery P. The adaptation of written self-management plans for children with asthma. J Adv Nurs 2003;41:444-53.

21. Ahmed S, Ernst P, Tamblyn R, Colman N. Validation of The 30 Second Asthma Test as a measure of asthma control. Can Respir J 2007;14:105-9.

22. Wensley D, Silverman M. Peak flow monitoring for guided selfmanagement in childhood asthma: A randomized controlled trial. Am J Respir Crit Care Med 2004;170:606-12.

23. Yoos HL, Kitzman H, McMullen A, Henderson C, Sidora K. Symptom monitoring in childhood asthma: A randomized clinical trial comparing peak expiratory flow rate with symptom monitoring. Ann Allerg Asthma Immunol 2002;88:283-91.

24. Letz KL, Schlie AR, Smits WL. A randomized trial comparing peak expiratory flow versus symptom self-management plans for children with persistent asthma. Pediatric Asthma Allergy \& Immunology 2004; 17:177-90.

25. Gervais P, Larouche I, Blais L, Fillion A, Beauchesne M-F. Asthma management at discharge from the emergency department: A descriptive study. Can Respir J 2005;12:219-22.

26. Cooper WO, Hickson GB. Corticosteroid prescription filling for children covered by Medicaid following an emergency department visit or hospitalization for asthma. Arch Pediatr Adolesc Med 2001;155:1111-5.

27. Halm EA, Mora P, Leventhal H. No symptoms, no asthma: The acute episodic disease belief is associated with poor self-management among inner-city adults with persistent asthma. Chest 2006;129:573-80.

28. Chapman KR, Ernst P, Grenville A, Dewland P, Zimmerman S. Control of asthma in Canada: Failure to achieve guideline targets. Can Respir J 2001;8:35A-40A.

29. Conseil du médicament Québec. Plan d'action pour l'asthme. <www.cdm. gouv.qc.ca> (Version current at September 15, 2007). 


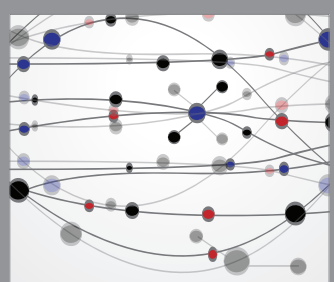

The Scientific World Journal
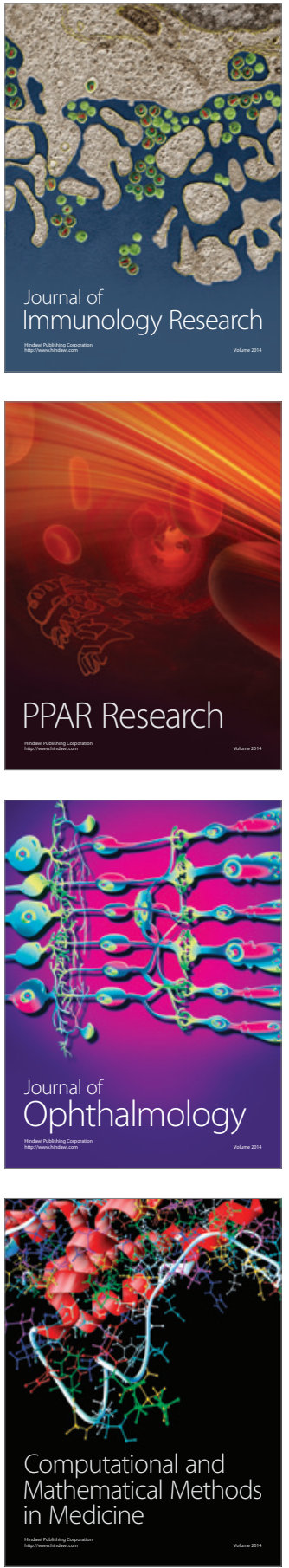

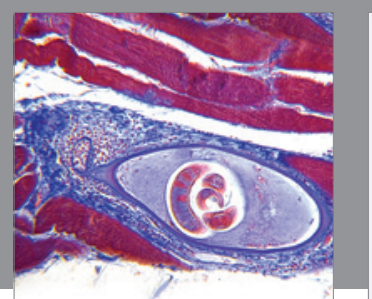

Gastroenterology Research and Practice

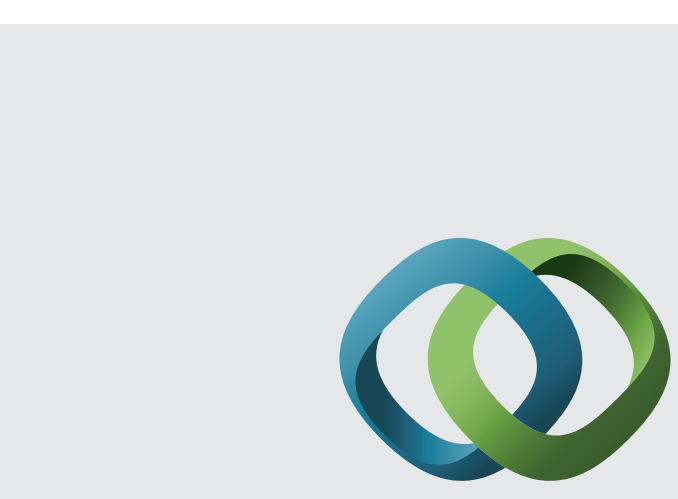

\section{Hindawi}

Submit your manuscripts at

http://www.hindawi.com
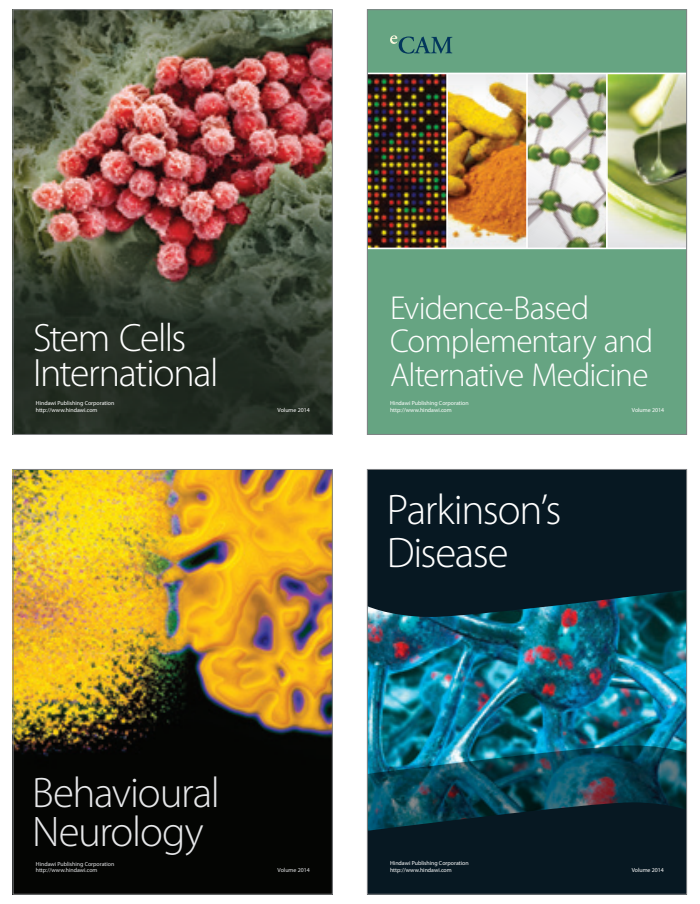
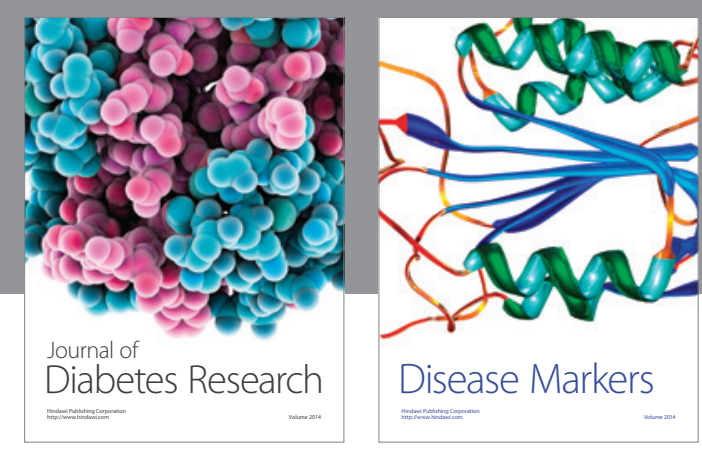

Disease Markers
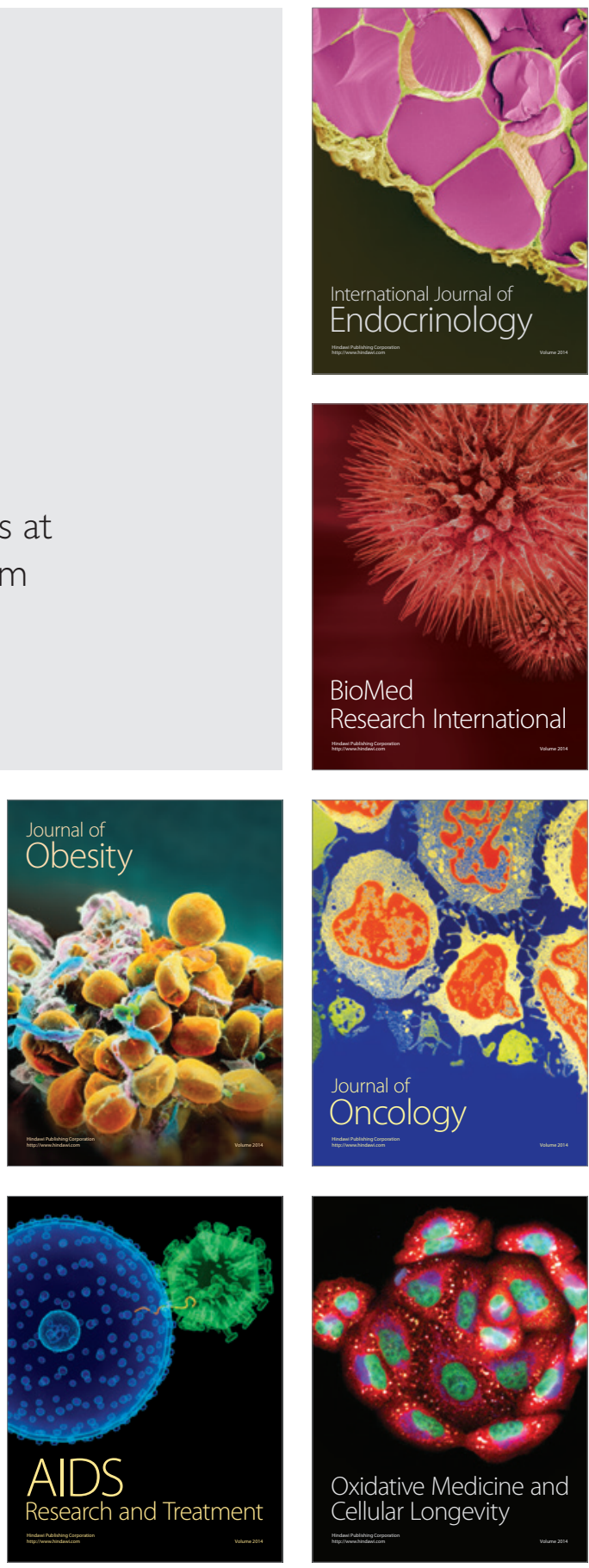